\title{
Uma correlação sobre o mito da queda em Platão e Paul TIllich
}

\author{
Edson Pereira da Silva ${ }^{1}$
}

\section{RESUMO}

O presente texto tem como objetivo geral tratar sobre o mito da queda em correlação com o pensamento de Paul Tillich com o pensamento de Platão. O texto esta delimitado especificamente em três tópicos no qual o último é o seu ápice. No primeiro tópico discorreremos sobre o método de Correlação de Paul Tillich como um instrumento na elaboração de perguntas e respostas para o problema da existência. No segundo trataremos sobre a transição da essência à existência. No terceiro analisaremos o mito da queda.

Palavras-chave: Correlação, filosofia, Paul Tillich, Platão, teologia.

\section{A CORRELATION ABOUT THE FALL MYTH ACCORDING TO PLATO AND PAUL TILLICH}

\section{ABSTRACT}

The paper has as general objective to present the fall myth in correlation with the Paul Tillich's and Plato's thought. The text is specifically delimited in three topics in which the last one is its apex. In the first topic we discuss Tillich's Correlation method as an instrument for questions and answers elaborations regarding the problem of existence. After that, we will work on the transition from essence to existence. Then, in a third part, we will analyze the myth of the fall.

Keywords: Correlation, philosophy, Paul Tillich, Plato, theology.

\section{Introdução}

Desde a Antiguidade, a existência é vista como um momento de transição em que se deu a perda de sua essência. Daí surgiu à busca

Mestre em Ciências da Religião pela UNICAP, graduado em Teologia pela UMESP e graduado em Pedagogia pela UNOPAR. E-mail: edson.cienciasdasreligioes@gmail.com. 
humana por um caminho (método) no qual possibilitasse a compreensão da causa de sua essência e de sua existência. Para que deste modo obtivesse respostas para suas perguntas.

À vista disso, o presente trabalho busca em primeiro lugar, discorrer sobre a importância do método de Correlação de Paul Tillich, pelo qual o teólogo tem como instrumento para dialogar com as diversas criações culturais, que no nosso caso, será com a filosofia.

No segundo, veremos a concepção de Platão, na qual temos o início propriamente dito da questão sobre o ser essencial e existencial no pensamento filosófico do Ocidente e, na sequência, discorreremos sobre a correlação de Paul Tillich com a teologia e o existencialismo, que através do símbolo da queda a teologia pode representar a condição humana.

Por fim, analisaremos a questão do mito da queda em correlação com Platão e Paul Tillich. Em Platão nosso estudo se dará a partir de dois mitos: o primeiro contido no livro Fedro, sobre a parelha alada e, o segundo, no livro A República, sobre Er. Em Tillich, nossa análise será do ponto de vista da narrativa bíblica e da teologia de Platão.

\section{Correlacionando a dimensão religiosa com as esferas culturais}

Para fazer uma análise da situação humana, é de fundamental importância o emprego de todos os instrumentos metodológicos disponíveis, através de perguntas e respostas existenciais em que haja correlação.

Segundo Tillich, a mensagem cristã deve satisfazer duas necessidades básicas: "a afirmação da verdade da mensagem cristã e a interpretação desta verdade para cada nova geração. A teologia oscila entre dois polos: a verdade eterna de seu fundamento e a situação temporal que esta verdade eterna deve ser recebida" (TILLICH, 2005, p.21). Em seu método, este autor procura satisfazer estas duas necessidades buscando explicar os conteúdos da fé cristã através de perguntas existenciais e de respostas teológicas.

O método de correlação pode ser aplicado de três maneiras: "Ele pode designar a correspondência de diferentes séries de dados, como registros estatísticos. Pode designar a interdependência lógica de concei- 
tos, como em relações polares, e pode designar a interdependência real de coisas ou eventos em conjuntos estruturais" (TILLICH, 2005, p.74).

$\mathrm{Na}$ teologia, estes três sentidos têm uma aplicação fundamental, como: correlacionar os símbolos religiosos e aquilo que eles simbolizam os conceitos lógicos que denotam o humano e aqueles que denotam o divino e correlacionar no sentido fatual entre a preocupação última e aquilo que ele se preocupa como questão última.

O método de correlação consiste em analisar todos os problemas últimos que envolvem a vida em sua concretude a partir de perguntas existenciais cujas respostas encontram-se nos símbolos cristãos. Segundo o autor:

Ao usar o método de correlação, a teologia sistemática procede da seguinte maneira: faz uma análise da situação humana a partir da qual surgem perguntas existenciais e demonstra que os símbolos usados na mensagem cristã são as respostas a estas perguntas (TILLICH, 2005, p.76).

Quando se refere aos símbolos religiosos, nesse caso, Deus, o autor entende como um símbolo fundamental naquilo que nos toca de forma incondicional. Por isso toda crença tem como fundamento este símbolo que é universalmente válido. Ele define os símbolos religiosos de "dimensão profunda da realidade, fundamento de todas as demais dimensões e de todas as outras profundidades" (TILLICH, 2009, p.102).

O símbolo propicia a compreensão de níveis da realidade que seriam impossíveis de serem expressos por outra forma de conhecimento. Permite o entrecruzamento dimensional e estrutural da alma com a realidade circundante. Manifesta-se de forma imperceptível, ou seja, de forma inconsciente no indivíduo e na coletividade tomando todas as dimensões.

O ser humano, desde que entrou em contato com o seu mundo externo se deparou com duas questões fundamentais para fazer uma reflexão sobre si. A primeira é a compreensão de que ele faz parte desse mundo, a segunda é a estranheza causada por não conhecê-lo e compreendê-lo em sua totalidade.

A consciência de existir o levou a entender que ele é a porta de acesso para realidade. Por isso ao longo da história criou vários mé- 
todos de interpretação para analisar sua situação existencial e a forma do mundo a sua volta. Para Tillich,

[...] A análise da situação humana emprega materiais disponibilizados pela autointerpretação criativa do ser humano em todos os âmbitos da cultura. A filosofia contribui, mais a poesia, o drama, o romance, a psicoterapia e a sociologia. O teólogo organiza estes materiais em relação com a resposta dada pela mensagem cristã (TILLICH, 2005, p.76-77).

Discorrendo sobre a importância desse método e sua abrangência, Cunha faz a seguinte descrição:

A novidade de Tillich consiste na amplitude que ele dá ao método, ou seja, a vida e o seu pensamento de fronteira propiciam correlacionar as situações reais da vida cotidiana com a diversidade de saberes, abrindo espaços para largas contextualizações e aplicações. Com ele, o método da correlação se tornou princípio hermenêutico em que o fazer teológico está fundamentado numa correlação epistemológica entre razão e Revelação, razão e fé, filosofia e teologia. (CUNHA, 2015, p.237-238).

Deste modo, faremos, a seguir, uma análise sobre essência e existência sob a ótica da filosofia e da teologia pelas quais poderemos ampliar nossas contextualizações e aplicações sobre a nossa existência e sobre o mundo a nossa volta.

\section{Essência e existência: trasição para o mito da queda}

Desde os primórdios do pensamento filosófico e religioso, a existência humana, é vista como uma "queda" daquilo que outrora constituía a sua essência. Na filosofia antiga, Anaximandro, Heráclito, Parmênides, os órficos e os pitagóricos apontaram que a realidade é constituída de dois níveis: um essencial e outro existencial. A conclusão que chegaram ao serem confrontados com o mundo era a de que o ser humano necessitava de uma realidade última.

Com Platão, o ser essencial e existencial, será visto como problema ontológico e ético, que até o último estágio do mundo antigo será dominante no pensamento filosófico Ocidental. O contraste entre o mundo cognoscível das ideias (essencial) e o visível dos sentidos (existencial) é nítido. Em Platão, a existência 
é o reino da mera opinião, do erro e do mal. Ela carece de verdadeira realidade. $\mathrm{O}$ verdadeiro ser é essencial, que está situado no âmbito das idéias eternas, isto é, nas essências. Para chegar ao essencial, o ser humano deve erguer-se acima da existência. Ele deve voltar ao âmbito das essências, do qual caiu na sua existência. Desta forma, a existência do ser humano, seu estar fora de potencialidade, é vista como uma queda daquilo que o ser humano é essencialmente. O potencial é o essencial, e existir, isto é, estar fora da potencialidade, é a perda da verdadeira essencialidade. (TILLICH, 2005, p. 317-318).

$\mathrm{Na}$ escolástica, a doutrina platônica foi aceita (com exceção de Deus que está além da essência e existência) em sua forma dualista de contraposição entre essência e existência. O abismo entre essência e existência como consequência dessa ruptura caracterizará o ser humano e o mundo.

No Renascimento e no Iluminismo, a existência como o estar fora da essência será substituída através da efetivação e da realização das potencialidades humanas, seja no controle ou na transformação do universo. A ciência, a educação e a política seriam os instrumentos que tornariam possível a superação da existência sobre a essência. Segundo esta descrição:

Na existência, o ser humano é aquilo que é ele é na essência - o microcosmo no qual estão conectados os poderes do universo, o portador da razão crítica e construtiva, o construtor de seu mundo e o fazedor de si mesmo como efetivação de sua potencialidade. A educação e a organização política superarão o atraso que sofre a existência em relação à essência (TILLICH, 2005, p.319).

Essa forma de existência do ponto de vista filosófico deu origem a uma forma de essencialismo, que acabou transformando a existência em sua própria essência. Seu apogeu se deu na filosofia clássica alemã com Hegel, que afirmava que a história do mundo é lugar onde a autorealização da mente divina acontece e a existência torna-se a própria manifestação da essência. Contra esse essencialismo hegeliano, o existencialismo oriundo dos séculos XIX e XX torna-se um protesto.

Desde o século XIX o divisor de águas e ponto de partida para a crítica da religião cristã será Hegel, e Nietzsche, o seu ápice. Tillich 
em sua Teologia Sistemática quando trata da relação da teologia e da filosofia deixa bem claro esse problema:

[...] toda a filosofia moderna é cristã, mesmo que seja humanista, ateísta e intencionalmente, anticristã. Nenhum filósofo que vive dentro da cultura ocidental cristã pode negar sua dependência dela. [...] A visão moderna da realidade e sua análise filosófica diferem das dos tempos pré-cristãos, estejamos ou não determinados existencialmente pelo Deus do Monte Sião e pelo Cristo do Monte Gólgota. Nosso encontro com a realidade agora é distinto; a experiência tem dimensões e direções diferentes daquelas do clima cultural da Grécia. Ninguém é capaz de sair deste círculo "mágico". Nietzsche, que tentou fazê-lo, anunciou a vinda do Anticristo. Mas o Anticristo é dependente do Cristo contra o qual ele se levanta (TILLICH, 2005, p.43-44).

Os gregos primitivos que Nietzsche tanto evocava como contraposição ao cristianismo foram os que prepararam inconscientemente a vinda do Cristo através de suas questões últimas respondidas em suas categorias. A filosofia moderna não é pagã assim como seu ateísmo e anticristianismo, pois, são termos de origem cristã - a filosofia moderna traz a marca e o caráter indelével da tradição cristã:

Os primitivos gregos, por cuja cultura Nietzsche ansiava, não tiveram que combater o Cristo. De fato, eles preparam inconscientemente sua vinda ao elaborar as questões às quais ele deu a resposta e as categorias nas quais a resposta podia ser expressa. A filosofia moderna não é pagã. $\mathrm{O}$ ateísmo e o anticristianismo não são pagãos. Eles são anticristãos em termos cristãos. As marcas da tradição cristã não podem ser deletadas; elas são character indelebilis ["caráter indelével"] (TILLICH, 2005, p.44).

Contudo, o ponto decisivo para a crítica da religião advém da esquerda hegeliana. Ela surge como uma virada em decorrência da ambiguidade do conceito hegeliano de superação. Seria decisiva para a destruição da filosofia e da religião cristã. Para estes críticos um dos erros básicos do pensamento de Hegel foi acreditar na superação da alienação humana. Isto se justifica porque a situação atual da existência humana é ela própria um estado de alienação.

Na própria filosofia de Hegel é possível distinguir pelo menos três fases em sua evolução as quais passam por: Feuerbach e Ruge; B. Bauer e Stirner; Marx e Kierkegaard. Contudo, sobre a terceira fase, a 
expressão de Karl Löwith aponta os extremos advindos desta situação em que "Marx e Kierkegaard extraíram consequências extremas da situação alterada: Marx destruiu o mundo burguês-capitalista e Kierkegaard o burguês cristão" (LÖWITH, 2014, p.84).

No entanto, estes sistemas são antagônicos na forma de versar sobre esta problemática. Enquanto a teologia tem sua proposta de salvação mediada por uma entidade metafísica, a filosofia, a busca por si mesma.

Como Deus se constitui uma razão última da preocupação humana implica dizer que o pensar e o fazer teológico e filosófico surgem de uma preocupação última e holística da experiência humana.

Nisto a filosofia e a teologia estão ontologicamente correlacionadas (estrutura do ser, as categorias e os conceitos descritos sobre ela) com aquilo que é denominado de questão última — Deus. É o que Tillich procura responder como um problema teológico e filosófico não resolvido, ou seja, ontológico. Isto é decorrente da formulação da crítica de Hegel à religião e sobre o objeto da teologia e filosofia: Deus, da crítica dos seus seguidores e da cisão radical destes com o seu pensamento.

Em Hegel percebemos que:

O objeto da religião, assim como o da filosofia, é a verdade eterna em sua própria objetividade, Deus e nada além de Deus e a explicação de Deus. A filosofia só se explica quando explica a religião. Ela é, como a religião, ocupação com esses objetos, é o espírito pensante que penetra esse objeto, a verdade (apud, LÖWITH, 2014, p. 370).

A partir deste contexto o símbolo da "queda" na linguagem mítica de Gênesis 1-3 é de fundamental importância para a compressão da correlação entre a teologia e o existencialismo (filosofia). Como o existencialismo constitui uma análise da condição humana, junto com a teologia deveria aliar-se na redescoberta dos elementos da natureza humana em suas manifestações inconscientes ou conscientes suprimidas pela psicologia, por isso, o

existencialismo e a teologia contemporânea deveriam se aliar na redescoberta dos elementos da natureza do ser humano que foram suprimidos pela psicologia da consciência e analisar o caráter da existência em todas as suas manifestações, tanto inconscientes quanto conscientes (TILLICH, 2005, p.323). 
No âmbito religioso o "existencialismo é o golpe de sorte da teologia cristã, pois ele ajudou a redescobrir a interpretação cristã clássica da existência humana" (TILLICH, 2005, p. 322-323). Em sua correlação com a teologia, o existencialismo apresenta o símbolo da "queda" como um capítulo decisivo na tradição cristã. Assim, "a teologia deve representar a "queda" como um símbolo para a situação humana em todos os tempos e não como relato de um evento que aconteceu "muito tempo atrás"." (TILLICH, 2005, p.324). Este símbolo tem um significado que vai além da interpretação cristã da queda de Adão porque é de âmbito universal.

Além disso, na teologia da religião é possível identificar a universalidade desse símbolo como uma questão última, pois se trata da condição humana em seu estado de alienação.

Segundo Geffré:

É notável que cada grande religião considere a condição humana, de modo geral, como um estado sob o signo de uma falta, quer essa situação deficiente seja compreendida como a consequência de uma queda, ou desobediência a Deus, quer como o fato de viver na ilusão das aparências fenomenais, ou como um mal-estar oriundo do fechamento em si mesmo de um ego limitado. Ora, essa finitude é experimentada em contraste com uma condição melhor que é a de estar em relação direta com o mistério de uma Realidade última, que será designada por diversos nomes: Javé, o Deus-Trindade, Alá, Brama, Vishnu, Shiva, ou o Nirvana, o Vazio. Quer dizer que, seja qual for nossa opinião sobre a existência, ou não, dessa Realidade última, não basta considerar as religiões somente como produtos da religiosidade humana, ou projeções condicionadas por determinada situação da cultura: elas surgem como respostas ao apelo de uma realidade misteriosa (GEFFRÉ, 2013, p.160-161).

Essa realidade misteriosa ao longo da história do pensamento humano foi descrita de forma vívida nas religiões e "é a expressão mais profunda e mais rica da consciência que o ser humano possui de sua alienação existencial e nos fornece o esquema no qual se pode discorrer sobre a transição da essência à existência" (TILLICH, 2005, p.326).

Essa transição da essência para existência evoca o mito da queda que analisaremos a seguir. 


\section{O mito da queda}

No mito da queda, encontramos o elemento moral e trágico do ser humano na transição do ser essencial ao do ser existencial. Nisto, é manifesta a universalidade de sua finitude. Por isso, é possível afirmar: essa transição é um fato original. De modo que não pode ser interpretada em seu sentido literal, tanto no que se refere ao tempo, quanto ao seu aspecto histórico.

Significa dizer que a originalidade deste fato, portanto, sua validez, conforme expressa na linguagem mitológica aponta para um fenômeno que vai além do tempo e do espaço, logo da história.

Contudo, é no tempo e no espaço no qual existimos em nossa relação com o mundo que, como evento histórico, o elemento moral e trágico do ser humano pode ser percebido, sentido, observado, expresso, vivido e descrito como um fato, como um acontecimento de âmbito universal que

[...] apresenta um caráter ético-psicológico e reflete a experiência diária de pessoas sob condições culturais e sociais peculiares. Contudo, ela reivindica uma validez universal. A predominância dos aspectos psicológicos e éticos não exclui outros fatores na estória bíblica (TILLICH, 2005, p.332).

Além de seu aspecto psicológico e ético, a narrativa bíblica apresenta de forma velada outro mito que aponta para o caráter cósmico da queda, seus pressupostos e implicações. Em sua dimensão:

O mito cósmico reaparece na Bíblia tanto na forma de luta que trava o divino contra os poderes demoníacos e os poderes do caos e das trevas quanto no mito da queda dos anjos e na interpretação que vê na serpente do Éden a corporificação de um anjo caído. Todos esses exemplos apontam para os pressupostos e implicações cósmicas da queda de Adão (TILLICH, 2005, p. 332).

No entanto, "a ênfase mais consistente no caráter cósmico da queda é dada no mito da queda transcendente das almas. Embora tenha provavelmente origem órfica, foi relatado pela primeira vez por Platão ao contrastar essência e existência" (TILLICH, 2005, p.332).

Tillich encontra no pensamento de Platão uma correlação entre a teologia da queda (mitologia) e o problema da essência e existência 
(filosofia). Essa mesma correlação entre mito, filosofia e teologia em Platão é percebida na própria tradição filosófica.

Proclo, em sua obra, Teologia Platônica, no seu programa filosófico, considera-se ligado e descendente de uma doutrina espiritual na qual Platão seria "aquele que desvela os objetos da filosofia, como um hierofante, nos mistérios, desvela os objetos sagrados" (BRISSON, 2014, p.161).

Segundo Proclo, a sua tradição teológica tem algumas etapas. Plotino como o seu primeiro exegeta e tradutor da doutrina platônica, logo depois seus discípulos, Amélio e Porfírio, sucedidos por Jâmblico e Teodoro de Asine até seu mestre Siriano e "todos os outros", neste caso Prisco e Jâmblico II. Estes, na sua obra, são apresentados como participantes da filosofia platônica. As obras de Platão são consideradas escrituras sagradas e estes, como exegetas da sua escritura.

$\mathrm{Na}$ escola neoplatônica de Atenas encontra-se uma teologia em formação cujo principal postulado e fundamento era este: Platão é um teólogo.

E esse postulado define uma tarefa dupla: extrair da obra de Platão essa teologia e mostrar que ela está de acordo com todas as outras teologias: a de Pitágoras, a dos Oráculos caldeus, a de Orfeu e as de Homero e Hesíodo. A tarefa do intérprete, seja ela aplicada à filosofia ou à poesia, é assimilada à do mistagogo que, nos mistérios, guia o postulante na iniciação e na epopeia (BRISSON, 2014, p.162).

Deste modo, Platão seria o guia espiritual de suas tradições, através de seus escritos considerados como revelação divina. Além disso, eles enalteciam estes escritos como uma escritura sagrada e chegaram a experimentar, no cerne de suas almas, uma elevação do próprio pensamento até o êxtase divino, dionisíaco.

No mito da parelha alada, no Fedro, Platão apresenta duas categorias de seres animados: imortais e mortais. Sobre esta última ele diz:

Mas quando perde as suas asas, decai através dos espaços infinitos até se consociar a um sólido qualquer, e aí estabelece seu repouso. Quando reveste a forma de um corpo terrestre, este começa, graças à força que lhe comunica alma, a mover-se. É a este conjunto de alma e de corpo que chamamos de ser vivo e mortal (PLATÃO, 2007, p.83). 
Platão, ao se referir ao ser inanimado, descreve a sua tendência para descer ao mundo dos sentidos, enquanto os imortais seguem em sua transcendência, isto é, em seu estado essencial, eterno. Os mortais tendem à imanência e consequentemente, ocorre um completo desequilíbrio em que a liberdade e o destino são apresentados no símbolo das asas. E como um carro desgovernado, acaba caindo e rompendo com sua essência eterna. Agora se torna existência, um ser finito e limitado como tal.

Além do Fédon, obra que Platão trata amplamente sobre imortalidade da alma, nos chama atenção o mito de Er como foi descrita em A República, na qual linguagem mítica é belamente explicitada em sua cosmogonia, teogonia e antropogonia.

A origem das almas, destino e liberdade, transcendência, essência e existência são temas presentes neste mito. Os deuses em sua essência são caracterizados por suas ambiguidades simbolizados em seus nomes. Na prática, se refletem no ser humano e na sua relação com o cosmo, com o próximo e consigo mesmo.

Se olharmos a obra em seu sentido amplo, teremos uma dimensão de outras questões que envolvem a existência humana. A política é a tônica que dirige todas as dimensões da vida humana como é o caso da justiça e da injustiça dentro das suas relações, inclusive a religião e a formação humana em sua plenitude numa forma ideal, que transcende o mundo dos sentidos.

Dentro desta perspectiva, o mito e toda a obra de Platão tratam de questões últimas. Isto é muito claro na relação dos mitos platônicos em dialética com a mitologia de Homero e Hesíodo, além dos mitos órficos que deram substância e forma na elaboração de sua teogonia, cosmogonia e antropogonia.

Nela, o ideal de cidade, de cidadão, de político é apontado em todas as relações do ser humano. Todas as questões explícitas e implícitas sobre a vida moral e sua relação com a sociedade são consideradas e discutidas. O mito se destaca pela forma como o passado, o presente e o futuro estão determinados e correlacionados com a existência humana, isto é, liberdade e destino. E é na eternidade onde receberão a sentença, os justos e os maus, conforme o julgamento dos seus juízes. 
É dentro deste contexto que Platão oferece uma nova forma de discurso. Elaborado a partir do mito, que confere à linguagem filosófica superioridade com relação à da mitologia de Homero e Hesíodo.

Falando de Platão e do seu interesse pelo mito, Brisson diz: "Se Platão se interessa tanto pelo mito, é porque ele quer romper seu monopólio a fim de impor o tipo de discurso, que ele pretende desenvolver, ou seja, o discurso filosófico, ao qual confere um estatuto superior" (BRISSON, 2014, p.42).

Platão, mesmo fundamentado no discurso filosófico, busca explicar a origem do mundo e do ser humano através das narrativas míticas e, que deste modo, são as fontes originárias do seu pensamento filosófico: é o que demonstra no mito de Er.

No mito, são as almas que, desde a eternidade, escolhem a forma e a condição de como será a sua existência aqui na terra, seja para o bom ou para o mau destino. Ao se depararem com as filhas da deusa Necessidade: as Moiras, o hierofante, tira de seus joelhos os destinos e os modelos de vida e os lançam para cada alma escolher de qual forma deseja viver aqui na terra, conscientes de sua ligação com a Necessidade, à qual seu passado, presente e futuro estão condicionados. É o que o hierofante soa na voz de Láquesis que diz:

Almas efêmeras, ides começar uma nova carreira e renascer para a condição mortal. Não é o gênio que vos escolherá, vós mesmos escolhereis vosso gênio. Que o primeiro designado pela sorte seja o primeiro a escolher a vida a que ficará ligado pela necessidade. A virtude não tem senhor: cada um de vós, consoante a venera ou desdenha, terá mais ou menos. A responsabilidade é daquele que escolhe. Deus não é responsável (PLATÃO, 2000, p. 348-349).

Enquanto no mito de Fedro das parelhas aladas, as almas tendem a cair para o mundo da matéria, o que indica certa inclinação dos mortais, para a queda, no mito de Er, a condição existencial de todo ser humano é fruto de sua escolha.

Logo, seu destino e sua efetivação aqui na terra para aquilo que é ambíguo como o bem e o mal, para ser justo e injusto, tem na sua escolha, isto é, sua liberdade, seu destino final. Significa dizer que a transição da essência para a existência, no mito da queda transcen- 
dente, é o resultado da livre escolha de cada ser humano. E Deus não pode interferir, por isso: não pode ser responsável pelas condições ou consequências daquilo que foi, do que é e do que vem a ser a vida de cada ser humano.

A liberdade, a partir deste mito, é representada na vida e em cada ação individual, como um destino universal. Por isso, para Tillich, tanto a narrativa bíblica quanto a narrativa de Platão apontam para o caráter trágico e universal da existência em sua efetivação. Cada ato do indivíduo como ser caído, alienado, é descrito como sua condição universal, onde destino e liberdade, tragédia e responsabilidade são inerentes a todos os seres humanos.

Isto comprova o que a psicologia e a sociologia analítica mostraram a partir de uma base empírica desta descrição:

Tanto a psicologia analítica quanto a sociologia analítica nos mostram como o destino e a liberdade, a tragédia e a responsabilidade estão entrelaçados em todo ser humano desde a primeira infância e em todos os grupos sociais e políticos ao longo da história da humanidade (TILLICH, 2005, p.334).

Para Tillich, o caráter trágico e universal da existência em sua efetivação, se dá através de cada ato do indivíduo como ser caído, alienado. O mito da queda é a descrição da condição universal da humanidade, onde destino e liberdade, tragédia e responsabilidade são inerentes a todos os seres humanos.

\section{Considerações que não se esgotam...}

Desde que o ser humano entrou em contato com o seu mundo externo, ou seja, tornou-se existência, se deparou com dois problemas fundamentais: o primeiro é sobre a sua relação como parte desse mundo, o segundo é o sentimento estranho e incômodo causado por não conhecê-lo e não compreendê-lo em sua totalidade.

A sua existência o impelia a busca de caminhos para que ele tivesse acesso à porta pela qual pudesse entender a realidade essencial. Por isso, ao longo da história criou vários métodos de interpretação para analisar sua situação existencial e essencial. 
Desta forma, conforme discorremos sobre a dimensão religiosa com as esferas culturais, a aplicação do método de correlação de Tillich busca analisar todas as questões últimas que envolvem a vida em sua concretude a partir de perguntas existenciais, cujas respostas encontram-se nos símbolos cristãos. Os símbolos propiciam a compreensão de níveis da realidade que seriam impossíveis de serem expressos por outra forma de conhecimento. Além disso, permitem o entrecruzamento dimensional e estrutural da alma com a realidade circundante. E se manifesta de forma imperceptível, ou seja, inconsciente no indivíduo e na coletividade.

E isso se dá a partir de três sentidos: primeiro, nos símbolos religiosos e aquilo que eles simbolizam; segundo, nos conceitos lógicos que denotam o humano e aqueles que denotam o divino; terceiro, no sentido fatual entre a preocupação última e aquilo que ele se preocupa como questão última.

Depois exploramos a questão da essência e existência. Em Platão, a existência é o reino equivocado da maneira de pensar, do erro, do mal e da ilusão. O ser essencial é aquele que está situado nas esferas das ideias eternas, que ele entende por essência e sua potencialidade. Desta maneira, para o ser humano voltar a sua essência e potencialidade deve se colocar acima da existência.

Em Tillich, o existencialismo se constitui num instrumento para a análise da condição humana e, junto com a teologia deveria aliar-se na redescoberta dos elementos da natureza humana em suas manifestações inconscientes ou conscientes suprimidas pela psicologia. $\mathrm{O}$ existencialismo para o autor facilitou a redescoberta cristã da interpretação clássica sobre a existência. Doravante o mito da queda deverá ser representado pela teologia como um símbolo que aponta para a situação do ser humano em todas as épocas.

E por último analisamos mito da queda. Para Platão no mito das parelhas aladas no livro de Fedro, as almas tendem a cair para o mundo da matéria, o que indica certa inclinação dos mortais, para a queda. Os mortais tendem à imanência na qual ocorre um completo desequilíbrio em que a liberdade e o destino são apresentados no símbolo das asas. No mito de Er vimos que a condição existencial de todo ser humano é fruto de sua escolha. Significa dizer que a transição da essência para a 
existência, ou seja, a queda, no mito de Er é o resultado da livre escolha de cada ser humano. A partir deste mito, a liberdade é representada como um destino universal na vida e em cada ação individual.

Para Tillich no mito da queda o elemento moral e trágico do ser humano é manifestado na universalidade de sua finitude. Expõe um caráter tanto ético como psicológico, que reflete na experiência cotidiana das pessoas tanto em suas condições culturais como sociais. Além de seu aspecto psicológico e ético, encontramos na narrativa de forma velada outro mito, que aponta para o caráter cósmico da queda na forma de uma batalha travada entre Deus e os poderes demoníacos. No entanto, o que é mais plausível sobre o caráter cósmico da queda é o mito da queda transcendente das almas, conforme escrito no livro de Platão, Fedro.

Todavia, no mito, o ser humano como essência e existência, ainda é um mistério. A linguagem dos mitos não se esgota em interpretações filosóficas, psicológicas e teológicas. Os modelos dogmáticos, sistemáticos e epistemológicos criados ao longo da história: esqueceram que as profundas e infindas lacunas no e do ser humano e da sua relação com o Universo, permitem apenas uma aproximação e não uma definição do que é o ser humano em sua essência e em sua existência.

\section{Referências}

BRISSON, Luc. Introdução à filosofia do mito. São Paulo: Paulus, 2014. CUNHA, Carlos Alberto Motta. O contributo do método da correlação de Paul Tillich à epistemologia da teologia pública no Brasil no contexto do pensamento complexo e transdisciplinar. Tese de Doutorado. Faculdade Jesuíta de Filosofia e Teologia, Departamento de Teologia. Belo Horizonte, 2015.

GEFFRÉ, Claude. De Babel a Pentecostes: ensaios de teologia inter-religiosa. São Paulo: Paulus, 2013.

LÖWIT, Karl. De Hegel a Nietzsche: A ruptura revolucionária no pensamento do século XIX: Marx e Kierkegaard. São Paulo: Editora da Unesp, 2014.

PLATÃO. A República. São Paulo: Editora Nova Cultural Ltda., 2000. Fedro. São Paulo: Editora Martin Claret, 2007.

TILLICH, Paul. Teologia da Cultura. São Paulo: Fonte Editorial, 2009. .Teologia sistemática. 5. ed. São Leopoldo: Sinodal, 2005. 